ÉGYPTE monde arabe

\section{Égypte/Monde arabe}

$34 \mid 1998$

Droits d'Égypte : histoire et sociologie

\title{
Yearbook of Islamic Law and Middle Eastern Law
}

\section{Baudouin Dupret}

\section{(2) OpenEdition}

\section{Journals}

\section{Édition électronique}

URL : https://journals.openedition.org/ema/1556

DOI : 10.4000/ema.1556

ISSN : 2090-7273

\section{Éditeur}

CEDEJ - Centre d'études et de documentation économiques juridiques et sociales

\section{Édition imprimée}

Date de publication : 31 décembre 1998

Pagination : 289-291

ISSN : 1110-5097

\section{Référence électronique}

Baudouin Dupret, "Yearbook of Islamic Law and Middle Eastern Law », Égypte/Monde arabe [En ligne], 34 | 1998, mis en ligne le 08 juillet 2008, consulté le 07 juillet 2022. URL : http:// journals.openedition.org/ema/1556 ; DOI : https://doi.org/10.4000/ema.1556

Ce document a été généré automatiquement le 7 juillet 2022.

Tous droits réservés 


\title{
Yearbook of Islamic Law and Middle Eastern Law
}

\author{
Baudouin Dupret
}

\section{RÉFÉRENCE}

Yearbook of Islamic Law and Middle Eastern Law, vol. 1(1995), 2(1996), 3(1997), édité par E. Cotran and Ch. Mallat, Kluwer Law International, 1995-1997

1 Il serait utopique de prétendre rendre compte exhaustivement du Yearbook édité par Eugene Cotran et Chibli Mallat, respectivement actuel et ancien présidents du CIMEL (Centre of Islamic and Middle Eastern Law), rattaché à la School of Oriental and African Studies. Il s'agit d'une entreprise ambitieuse visant à traiter du droit de manière à la fois thématique et géographique, dans une perspective disciplinaire aussi bien strictement juridique que plus largement socio-politique. Le Yearbook en est à sa troisième édition et il s'est de toute évidence imposé comme une publication majeure dans le champ des études juridiques sur un Moyen-Orient s'étendant de la Mauritanie à l'Indonésie.

2 Les volumes du Yearbook se subdivisent en cinq parties : articles, synthèses juridiques par pays, sélection de documents et de textes de loi, sélection d'affaires importantes, notes de lecture et notices diverses. La partie consacrée aux articles n'a pas d'unité thématique, au-delà du très vaste "droit islamique et proche-oriental ». On y trouve ainsi des textes touchant, comme celui de Schacht (vol.1), à l'histoire du droit islamique, à la dimension politique du droit, comme ceux de Kienle (nationalisme et droit de la nationalité, vol.1) et Kassim (citoyenneté en Palestine, vol.3), à des législations ponctuelles (Nauimi sur le système taxatoire qatariote, vol. 1 ; El Alami sur l'indemnité pour divorce en Jordanie et en Egypte et Zirari-Devif sur la loi organisant le régime de l'eau au Maroc, vol. 2), au droit commercial, essentiellement dans les pays du Golfe (Namison, vol. 1 ; El-Malik, vol. 2 et vol. 3 ; McArdle Mc Kinney, Macartney, vol. 3). On bénéficie également d'introductions à des systèmes de droit, comme les articles de 
Lau sur le Pakistan et de Mallat sur la justice constitutionnelle au Proche-Orient (vol. 1), de Dogru sur l'accès à la justice en Turquie (vol. 2), de Makec sur la justice au Soudan, d'Ibrahim sur le droit islamique en Malaisie ou de Moosa sur les perspectives de développement du droit islamique en Afrique du Sud (vol.3). Même les questions de droit international trouvent à être traitées (Al Bahama sur les conflits frontaliers maritimes dans le Golfe, vol. 1, et Al-Rimawi sur les colonies de peuplement dans les Territoires occupés par Israël, vol.3). Restent enfin des articles à forte teneur théorique, traitant en général de la nature du droit islamique et de ses références au droit positif (Bàlz, dans le vol.2, qui tente une approche systémique des relations sharî'a-qânûn, ou Sardar Ali, dans le vol. 3, qui enquête sur la nature sui generis de la personnalité juridique féminine). Pour autant qu'on n'y cherche donc pas de cohérences internes, les articles de cette première partie du Yearbook constituent une mine d'informations fort riche. On peut toutefois penser qu'un certain resserrement des thématiques ne nuirait pas à la qualité d'ensemble de l'ouvrage. À cet égard, on peut émettre le souhait tout personnel de voir cette première partie se structurer autour de deux axes principaux : les approches du droit par les sciences sociales et les études juridiques à proprement parler.

3 Les quatre autres parties du Yearbook ont une visée clairement informative et réussissent pleinement dans leur entreprise. Ce sont elles qui font l'originalité de cet annuaire et on peut, à cet égard, souhaiter qu'elles s'étoffent encore davantage. La deuxième partie présente une fiche synthétique des évolutions législatives et jurisprudentielles d'une petite vingtaine de pays: Egypte, Syrie, Irak, Jordanie, Palestine, Liban, Libye, Koweït, Arabie Saoudite, Émirats Arabes Unis, Bahrein, Qatar, Oman, Yémen, Iran, Algérie, Tunisie, Pakistan, Turquie, Soudan, Maroc. Si, dans le premier volume, ces fiches ont aussi tendu à présenter la structure judiciaire de chaque pays, elles se sont attachées ensuite à ne présenter que les lignes de faîte de leur développement juridique annuel. La troisième partie est exclusivement documentaire et propose une sélection de textes internationaux et de législations concernant les pays du Proche-Orient. On regrettera simplement que les dimensions civiles et pénales des différents droits fassent l'objet d'une moins grande attention que leurs dimensions commerciales. La quatrième partie propose le résumé d'une sélection de jugements et d'arrêts significatifs. C'est une innovation particulièrement heureuse qui contribue à une description de la vie juridique dans les pays des Proche-et Moyen-Orient totalement dégagée des vieux fantasmes orientalistes qui la réduisaient à ses relations avec le droit islamique-. À cet égard, on peut peut-être regretter que le titre de l'annuaire fasse référence, pour des raisons commerciales sans doute, au droit islamique. Le droit et la vie du droit sont particuliers aux différents pays de la région et la question islamique n'y est que marginale. La cinquième partie, qui apparaît dans le deuxième volume du Yearbook, est consacrée à des notes de lecture et à des informations diverses dont l'utilité n'est pas contestable. Ainsi en va-t-il, par exemple, des fiches signalétiques de différentes associations comme l'Union des juristes arabes, l'Association des juristes arabes, le Forum régional arabe (vol. 2) ou le Centre yéménite de conciliation et d'arbitrage (vol.3). En conclusion, il convient donc de saluer chaleureusement la publication du Yearbook of Islamic and Middle Eastern Law qui s'impose déjà comme une référence incontournable dans l'étude du droit des pays arabes et du Moyen-Orient. On regrettera sans doute que sa diffusion sort limitée par un prix de vente particulièrement élevé, qui toutefois n'excède pas de beaucoup le 
montant d'un abonnement à un trimestriel dont le volume de pages annuel est pourtant comparable.

\section{AUTEUR}

\section{BAUDOUIN DUPRET}

CNRS/Cedej 